\title{
Effect of lead and zinc oxides on the thermal properties of tellurite glass systems
}

\begin{abstract}
Thermal properties of binary $(\mathrm{PbO})_{\mathrm{x}}\left(\mathrm{TeO}_{2}\right)_{1-\mathrm{x}, \mathrm{x}}=0,0.10,0.15,0.20,0.25,0.30 \mathrm{~mol} \%$ and ternary $[\mathrm{ZnO}]_{\mathrm{y}}\left[\left(\mathrm{TeO}_{2}\right)_{0.7}-(\mathrm{PbO})_{0.3}\right]_{1-\mathrm{y}}$ with $\mathrm{y}=0.15,0.17,0.20,0.22,0.25 \mathrm{~mol} \%$ were measured. The glass systems were prepared using the conventional melt-quenching technique. The thermal properties of the glasses were investigated using differential scanning calorimetry (DSC) analysis. Thermal analysis of the glasses was realized regarding the glass transition temperature $\left(T_{\mathrm{g}}\right)$, glass crystallization temperature $\left(T_{\mathrm{c}}\right)$, and glass stability against crystallization $(\Delta T)$. Quantitative analysis of the $T_{\mathrm{g}}$ of the glass samples was discussed based on the total number of bonds per unit volume and average stretching force constant of each bond in each glass composition. Debye temperature, softening temperature and thermal expansion coefficient, $\left(\alpha_{\mathrm{P}}\right)$ of the glass samples were calculated based on the measured ultrasonic velocities and densities data. The addition of $\mathrm{PbO}$ improved the thermal properties in the binary $\mathrm{PbO}-\mathrm{TeO}_{2}$ glasses, while the addition of $\mathrm{ZnO}$ showed the different trend to the thermal properties of the ternary $\mathrm{ZnO}-\mathrm{PbO}-\mathrm{TeO}_{2}$ glasses.
\end{abstract}

Keyword: Thermal properties; Lead tellurite glass; Zinc lead tellurite glass 